Personalidade Acadêmica Homenageada:

Carlos Aurélio Mota de Souza (Universidade Ibirapuera - UNIB)

\title{
RESPONSABILIDADE SOCIOAMBIENTAL EMPRESARIAL (RSAE): LUCROS E BEM ESTAR SOB A ÓTICA DO O PRINCÍPIO DA EFICIÊNCIA ECONÔMICO-SOCIAL (PEES)
}

\section{CORPORATE SOCIAL-ENVIRONMENTAL RESPONSIBILITY (CSER): PROFIT AND WEALFARE BY VIEW OF THE PRINCIPLE OF ECONOMIC AND SOCIAL EFFICIENCY (PESE)}

\section{EVERTON DAS NEVES GONÇALVES}

Doutor em Direito, na área de Direito Econômico pela Universidade Federal de Minas Gerais - UFMG/MG; Doctor en Derecho, área de Derecho Internacional Económico en la Universidad de Buenos Aires (UBA/Bs. As) - Argentina; Mestre em Direito, na área de Instituições Jurídico-Políticas pela Universidade Federal de Santa Catarina (UFSC/SC); Professor Titular do Centro de Ciências Jurídicas (CCJ) da UFSC atuando em Analise Econômica do Direito e em Direito Econômico nas Graduações em Direito e em Ciências Econômicas da UFSC. Coordenador do Centro de Estudos JurídicoEconômicos e de Gestão do Desenvolvimento (CEJEGD). Professor credenciado no Programa de Pós-Graduação em Direito (PPGD) da UFSC. E-mail: evertong@vetorial.net.

LISANDRO FIN NISHI

Doutorando em Direito pela UFSC. Professor da Universidade do Estado de Santa Catarina (UDESC). E-mail: lisandro.nishi@udesc.br.

\section{RESUMO}

O trabalho trata da Responsabilidade Socioambiental das Empresas (RSAE), no Brasil, destacando que tanto almejar o lucro como objetivo da empresa quanto promover o 


\section{Personalidade Acadêmica Homenageada:}

Carlos Aurélio Mota de Souza (Universidade Ibirapuera - UNIB)

bem estar social e ambiental são objetivos a serem alcançados na ação empresarial. O tema é contextualizado sob o enfoque do Princípio da Eficiência Econômico-Social (PEES) a partir da Análise Econômica do Direito (AED). Trata-se de pesquisa qualitativa exploratória, de procedimento monográfico, de abordagem dedutiva e técnica de pesquisa bibliográfica. Conclui pela relação do PEES com a RSAE segundo Direito, socialmente inclusor; progressista, eficiente; atento ao contexto econômicosocial, político e jurídico.

PALAVRAS-CHAVE: Responsabilidade Socioambiental da Empresa; Princípio da Eficiência Econômico-Social; Análise Econômica do Direito Empresarial.

\section{ABSTRACT}

The study treats about Corporate Social-Environmental Responsibility (CSER) in Brazil pointing that both crave the profit as the company's objective as promoting social welfare are objectives to be achieved in business action. The topic is contextualized under the focus of the Principle of Economic and Social Efficiency (PESE) and from the Economic Analysis of Law (EAL) view. This is an exploratory and qualitative research with monographic procedure; deductive approach and technique of bibliographical research. Concludes the relationship of PESE to CSER according to Law, socially inclusor; progressive, efficient; aware of the economic and social context, political and legal.

KEYWORDS: Corporate Social-Environmental Responsibility; Principle of Economic and Social Efficiency; Economic Analysis of Corporate Law. 


\section{Personalidade Acadêmica Homenageada:}

Carlos Aurélio Mota de Souza (Universidade Ibirapuera - UNIB)

\section{INTRODUÇÃO}

Diverge, a doutrina, no que tange ao impacto sobre os lucros das empresas quando estas adotam a ação em mercado com responsabilidade socioambiental ${ }^{1}$. Enquanto uma vertente defende que o objetivo da empresa é maximizar o lucro, o que geraria mais emprego, renda, eficiência econômica e; consequentemente, bem estar ambiental e social; outra vertente defende que se deve empreender com responsabilidade socioambiental. O argumento para a empresa não se engajar em responsabilidade socioambiental é que tal comportamento a afastaria de seu objetivo, qual seja, maximizar o lucro, cuja consequência levada ao extremo seria o fechamento da atividade empresarial. É crescente o número de empresas que adotam práticas de responsabilidade socioambiental, sendo assim reconhecidas as que vão além do exigido pela legislação, e cujo engajamento não é ocasional, tampouco apenas marketing. Ao menos teoricamente, é possível demonstrar que o investimento socioambiental pode acarretar tanto a piora no desempenho econômico e financeiro quanto pode melhorar tal desempenho, a depender da magnitude da modificação nos custos e receitas da empresa. Neste trabalho objetiva-se mostrar por via da Teoria Microeconômica da Firma, e através de pesquisa bibliográfica, que a empresa, quando atua com responsabilidade socioambiental, pode inclusive incrementar seus lucros, mesmo que de forma não intencional. Conclui-se que a adoção de práticas de responsabilidade socioambiental, em geral, tem provocado melhora no desempenho econômico e financeiro das atividades empresariais no Brasil.

Após apontamentos sobre o histórico, conceito e características, serão expostas as duas principais correntes que explicam o tema. Uma defendendo que a responsabilidade socioambiental da empresa consiste unicamente na prática de maximizar o lucro e; a outra, defendendo que a empresa deve ir além do objetivo de maximização de lucros, desenvolvendo práticas que beneficiem todas as partes interessadas: trabalhadores, acionistas, consumidores, comunidade próximas, entre

\footnotetext{
${ }_{1}^{1}$ Para fins do presente texto, entende-se que a responsabilidade social da empresa (RSE) envolve, também, preocupações ambientais (Responsabilidade Socioambiental da Empresa - RSAE).
} 
Personalidade Acadêmica Homenageada:

Carlos Aurélio Mota de Souza (Universidade Ibirapuera - UNIB)

outros. O tema é contextualizado sob o enfoque do Princípio da Eficiência EconômicoSocial (PEES) a partir da Análise Econômica do Direito (AED) para; por fim, concluirse pela relação do PEES com a RSAE segundo Direito, socialmente inclusor; progressista, eficiente; atento ao contexto econômico-social, político e jurídico. Tratase de pesquisa qualitativa exploratória, de procedimento monográfico, de abordagem dedutiva e técnica de pesquisa bibliográfica. Por meio de estudo teórico e de pesquisa bibliográfica, o artigo objetiva demonstrar que o engajamento em responsabilidade socioambiental não acarreta necessariamente a redução de lucros, sendo possível inclusive à empresa elevá-los como consequência deste engajamento. Os tópicos que seguem trazem a fundamentação teórica, apresentando os conceitos de maximização de lucros e de responsabilidade socioambiental corporativa. Em seguida, demonstrase que as "ferramentas" de maximização de lucros continuam sendo úteis em empresas que atuam com responsabilidade socioambiental. Ao final, as conclusões e as referências.

\section{LUCROS E RESPONSABILIDADE SOCIOAMBIENTAL EMPRESARIAL: APRECIAÇÃO GRÁFICA}

Ao questionar-se quanto ao possível engajamento em responsabilidade socioambiental, implicar redução do lucro das empresas, afastando-as do objetivo de maximização de lucros; verifica-se que a resposta pode ser negativa. Assim, exemplificativamente, suponha-se que uma empresa, não sendo engajada em responsabilidade socioambiental, passe a sê-lo. Desta forma, revisitando o Gráfico 1, a empresa (a) possui dada Curva de Custo Total (CT - linha cheia C) e de Receita Total (RT - linha cheia R); posteriormente, resolvendo, a referida empresa, atuar com responsabilidade socioambiental. Este engajamento implica em custo que provoca a elevação da Curva de Custo Total (linha tracejada $\mathrm{C}$ ), fato que reduz o lucro total, conforme se visualiza no Gráfico 1, lembrando-se, ainda, que o lucro é obtido pela distância entre a Curva de Receita Total e a Curva de Custo Total, podendo ser, 


\section{Personalidade Acadêmica Homenageada:}

Carlos Aurélio Mota de Souza (Universidade Ibirapuera - UNIB)

inclusive, negativa (prejuízo) quando a Curva de CT se encontra acima da Curva de RT.

Gráfico 1: Elevação da Curva de Custo Total

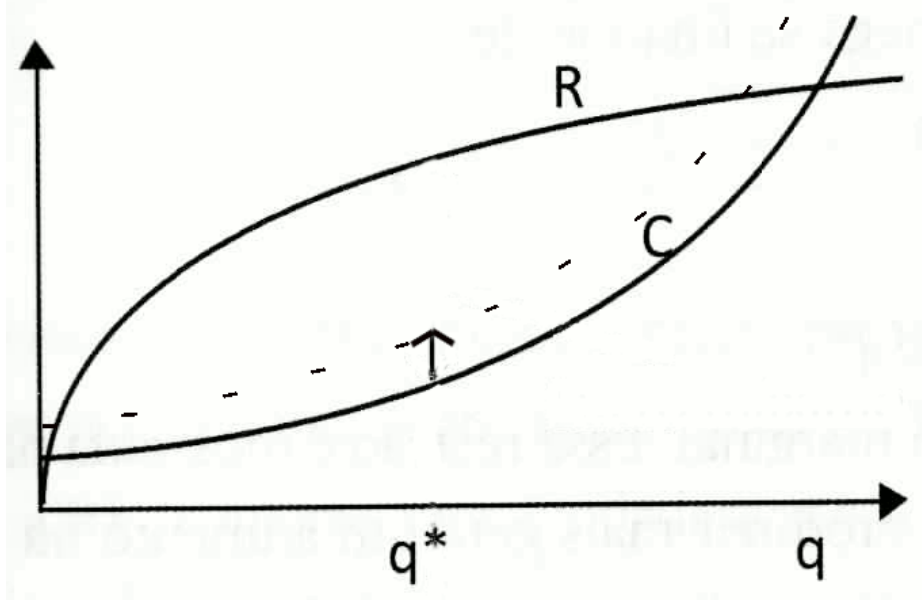

Fonte: Elaboração dos autores, adaptado de Guimarães e Gonçalves (2010).

Observa-se que o raciocínio desconsidera fato relevante, qual seja; as decisões tomadas pela empresa impactam não somente seus custos, mas, também, as percepções dos consumidores a respeito de suas atitudes. Isso significa que a "demanda" também pode ser afetada conforme a tomada de decisão por parte da empresa. Neste caso, pode-se afirmar que os consumidores, ao entenderem que a empresa possui preocupação social, podem preferir consumir produtos e serviços desta empresa em relação aos produtos e serviços de suas concorrentes. Graficamente, tem-se, também, o deslocamento da Curva RT (RT), conforme o Gráfico 2 que segue. 


\section{Personalidade Acadêmica Homenageada:}

Carlos Aurélio Mota de Souza (Universidade Ibirapuera - UNIB)

Gráfico 2: Elevação da Curva de Receita Total

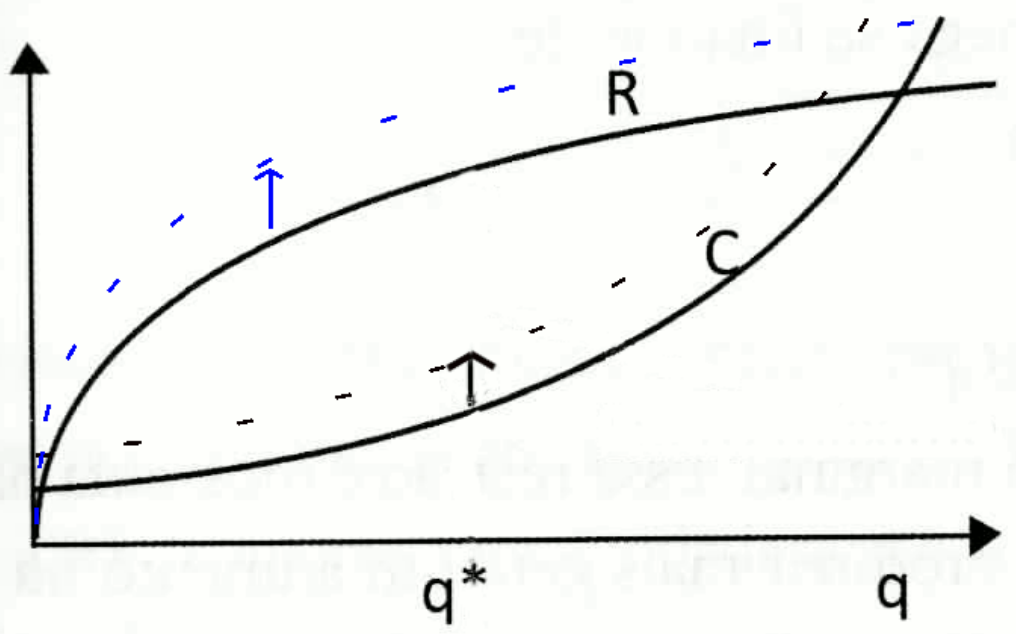

Fonte: Elaboração dos autores adaptado de Guimarães e Gonçalves (2010)

Com referido deslocamento da Curva de Receita Total (RT), o resultado da empresa pode implicar lucro inferior, igual ou até mesmo superior ao lucro obtido quando a empresa não adota práticas de responsabilidade socioambiental, pois dependerá do quanto será a elevação de seus custos e receitas. Todavia, é possível que, considerando o nível maximizador de lucros, o deslocamento da Curva de Receita promova elevação dos lucros da firma, sendo que a elevação das receitas ocorreria em função da elevação da demanda.

Gráfico 3: Deslocamento da curva de demanda

Preço

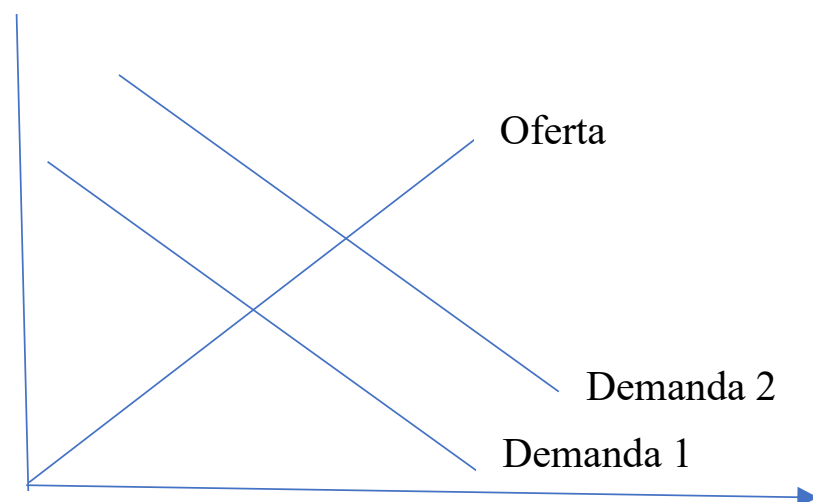

Fonte: Elaboração dos autores

Quantidade 


\section{Personalidade Acadêmica Homenageada:}

Carlos Aurélio Mota de Souza (Universidade Ibirapuera - UNIB)

Embora a elevação da demanda provoque elevação dos preços (salvo se a oferta, também, aumente em magnitude que mais do que compense a elevação da demanda; fato que, no caso em questão, não ocorre), não se pode dizer que os consumidores seriam prejudicados por esta elevação de preços, uma vez que estariam dispostos a pagar mais e de forma justa devido ao fato de a empresa estaria investindo em responsabilidade socioambiental.

Gonçalves e Guimarães (2010, p. 31) comentam que, frequentemente, empresas tomam decisões que, aparentemente, não maximizariam o lucro, a fim de, por exemplo, estabelecer reputação de longo prazo, ou ampliar a "fatia de atuação" no mercado vendendo a preço baixo por certo tempo ou ajudando a preservar o meio ambiente. Recordam, porém, que o objetivo de se obter lucro não pode ser totalmente ignorado, pois empresas que não buscam maximiza-lo não sobrevivem em longo prazo; ou seja, não é possível afastar-se de tal objetivo por muito tempo sob pena de fechamento da empresa.

A forma com que as empresas buscam a maximização de lucros está diretamente relacionada com a estrutura de seu mercado de atuação. Para fins deste estudo, hipoteticamente, adota-se a maximização de lucros segundo modelo aproximado da realidade quotidiana, qual seja, o modelo de concorrência monopolista; pois Passos e Nogami (2006) observam que "a diferenciação de produtos caracteriza a maioria dos mercados existentes". Em tais mercados, há livre entrada e saída de empresas e; ainda que se tratando de abstração teórica, explica-se, com considerável aproximação da realidade, o fato de que, a concorrência aumenta com grande facilidade caso os lucros, nesses mercados, estejam acima do lucro normal. Outra característica desta estrutura de mercado é que a Curva de Demanda é negativamente inclinada. Embora existam exceções, em geral, tal representação explica bem como as pessoas se comportam perante as variações de preço: quanto maior o preço, menor a quantidade demandada de um bem e vice versa. Trata-se, pois, de estrutura de mercado situada entre o monopólio e a concorrência perfeita, contendo elementos de ambas, em que existe grande número de compradores e de vendedores, o produto é diferenciado e há livre entrada e saída de players, na medida em que não há barreiras (legais ou econômicas) dificultando a entrada ou saída de 


\section{Personalidade Acadêmica Homenageada:}

Carlos Aurélio Mota de Souza (Universidade Ibirapuera - UNIB)

empresas no mercado. Por este motivo, eventual existência de lucro econômico acima do normal no curto prazo, atrai novos agentes econômicos que possuem informação perfeita sobre o mercado, reduzindo o lucro econômico no longo prazo (o lucro econômico de longo prazo é zero). Destarte, no curto prazo, a empresa pode obter lucro econômico, de acordo com o Gráfico 4 que segue.

Gráfico 4: Maximização de Lucros

(a)

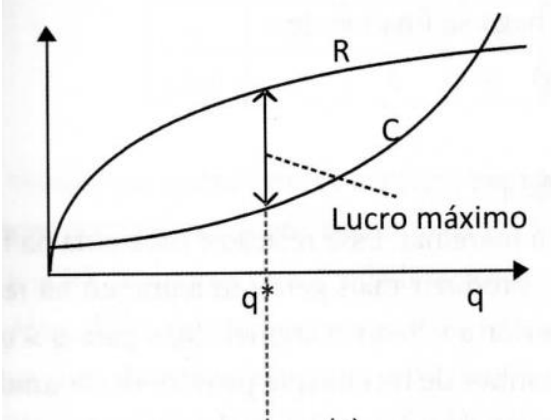

(c)

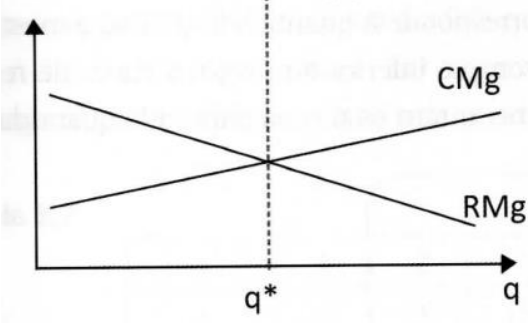

(b)

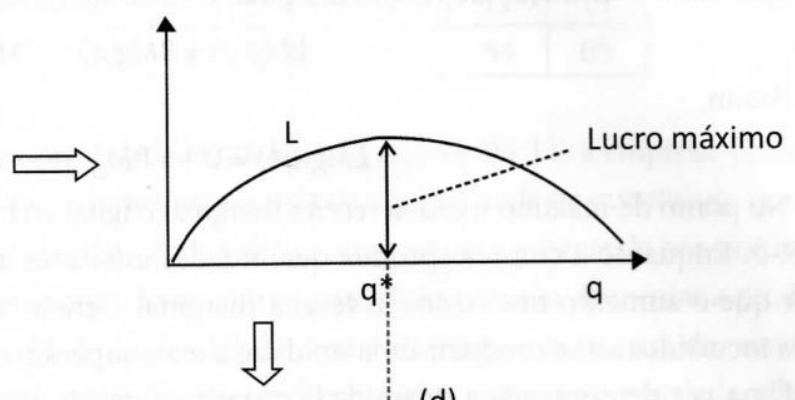

(d)

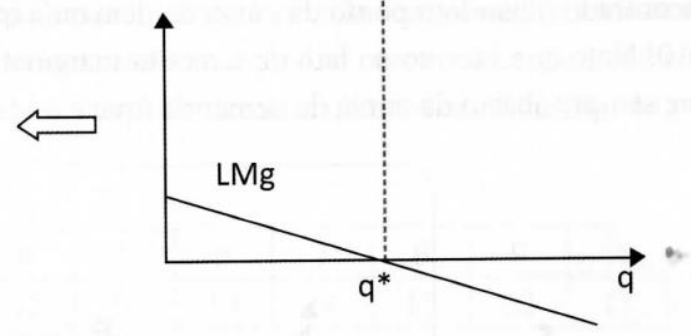

Fonte: Guimarães e Gonçalves (2010)

No Gráfico 4 (a), tem-se a Curva de Receita Total (RT) e a Curva de Custo Total (CT), sendo que (RT) é encontrada pelo produto do preço com a quantidade, e (CT) sendo a soma dos Custos Fixos Totais (CFT) com os Custos Variáveis Totais (CVT). Percebe-se que o lucro máximo é obtido quando a distância entre as duas curvas é máxima, ou seja, produzindo a quantidade $q^{*}$. No gráfico 4 (b) vê-se o comportamento da Curva de Lucro (CL), entendendo-se como lucro a diferença entre a receita total e o custo total. O gráfico 4 (c) evidencia, graficamente, a maneira de se encontrar a quantidade maximizadora de lucro $\mathrm{q}^{*}$ igualando-se a Receita Marginal $(\mathrm{RMg})$ ao Custo Marginal $(\mathrm{CMg})$, sendo que a $\mathrm{RMg}=\partial \mathrm{RT} / \partial \mathrm{q}$ e $\mathrm{CMg}=\partial \mathrm{CT} / \partial \mathrm{q}$. 


\section{Personalidade Acadêmica Homenageada:}

Carlos Aurélio Mota de Souza (Universidade Ibirapuera - UNIB)

É possível encontrar a quantidade maximizadora de lucro igualando-se o Lucro Marginal (LMg) a zero, o que pode ser visto no gráfico 4 (b). Nesse ponto de máximo da curva $\mathrm{LMg}$ tem-se $\mathrm{LMg}=0$, visto no Gráfico 4 (d).

Da Teoria Microeconômica exposta, depreende-se que o investimento socioambiental da empresa aumenta seus custos (Curva de Custo Total CT) implicando o fato de que, a mesma, terá de readequar-se para disputar junto aos demais players, em mercado concorrencial, a demanda. Duas consequências são possíveis, a saber: diminuição da margem de lucro, na impossibilidade de aumento dos preços ou majoração dos mesmos em virtude do aumento do grau de exigência da demanda por produtos socioambientalmente adequados.

\section{RESPONSABILIDADE SOCIOAMBIENTAL EMPRESARIAL (RSAE)}

Desde a Revolução Industrial e a ascensão do Sistema Capitalista o mundo tem percebido grandes mudanças econômicas, sociais e ambientais, além disso, a necessidade de obtenção de renda para sobreviver leva alguns a, simplesmente, deixar de lado o altruísmo, a ética, e até mesmo a legalidade, passando por cima de quem quer que seja, por quaisquer meios, em benefício próprio. Entretanto, nem todos caminham no mesmo sentido e, assim, tem crescido os defensores da RSAE. Tratase de defender a ideia de que as empresas têm obrigações socioambientais e; logo, não se deve pensar unicamente na obtenção de lucros.

Os tópicos que se seguem apresentam histórico; bem como, conceito e principais características da RSE, bem como, sua ingerência na esfera jurídica brasileira. São analisadas, ainda, as duas principais vertentes acerca de RSE. Em seguida, utiliza-se o "ferramental" metodológico da AED e defende-se a RSAE como sucedâneo do PEES para fins de situar o necessário marco teórico. E, por fim, os temas são entrelaçados para, de forma progressista e inclusora se concluir pela harmoniosa conjugação entre a RSE e a preocupação em função da preservação e defesa ambiental voltadas à sociedade e ao desenvolvimento sustentável conforme o Princípio da Eficiência Econômica-Social. 


\section{Personalidade Acadêmica Homenageada:}

Carlos Aurélio Mota de Souza (Universidade Ibirapuera - UNIB)

\subsection{HISTÓRICO, CARACTERÍSTICAS E CONCEITO DA RSE.}

Segundo Carroll (apud GARGIONI, 2009, p. 24) as noções teóricas e práticas relacionadas à RSE surgiram em momentos e países variados. Os autores Guimarães e Oliveira (2017, p. 102) esclarecem que a prática de responsabilidade socioambiental acontecia desde o Séc. XIX; mas, o início efetivo de uma mudança de comportamento revelando a RSE, nos EUA, ocorreu a partir de 1919, discutindo-se o tema em torno da decisão do caso Dodge versus Ford. Destarte, Henry Ford, presidente e acionista majoritário da Ford, contrariou os interesses dos demais acionistas sendo favorável à retenção de parte dos dividendos da empresa para o desenvolvimento de ações de caráter social, como investimentos na produção e aumento de salários. Contudo, a sentença foi favorável à Dodge afirmando que a organização empresarial deveria existir para beneficiar os acionistas, logo, o lucro não poderia ser utilizado para outros fins.

Para Tenório (2004, p.23) "os primeiros estudos teóricos sobre a responsabilidade social empresarial, desenvolvidos a partir dos pressupostos conceituais da sociedade pós-industrial surgiram em 1950." De Masi apud Tenório (2004, p.17) pondera que o processo de industrialização iniciado no Séc. XX trouxe problemas sociais e ecológicos, sendo que o crescimento das dimensões urbanas não ocorreu com a respectiva melhoria nas condições de vida dos cidadãos. Com este argumento, justifica-se, então, o envolvimento das empresas em questões sociais e ambientais. Em 1953, discutiu-se, nos EUA, a doação de recursos financeiros à Universidade de Princeton que culminou no surgimento da "Lei da Filantropia Corporativa" regulando o modo como as empresas deveriam promover 0 desenvolvimento social (GUIMARÃES, OLIVEIRA, 2017, p.103). Ainda, em 1953, foi lançada a obra Social Responsibility of the Businessman do economista Howard Rothmann Bowen que constitui marco para o estudo do tema, conforme pontua Gargioni (2009, p. 24).

Morcelli (apud GUIMARÃES, OLIVEIRA, 20017, p.103) num contexto mais contemporâneo e voltado às questões ambientais - destaca que Argila Ford Jr., enquanto presidente da Ford foi apoiado pelos acionistas e demais partes 


\section{Personalidade Acadêmica Homenageada:}

Carlos Aurélio Mota de Souza (Universidade Ibirapuera - UNIB)

interessadas em seu intento de caracterizar os negócios de suas empresas, também, como um serviço para a sociedade. $O$ entendimento de que a empresa teria função social junto à comunidade e comprometimento para com a preservação do meio ambiente passou a ser mais comumente defendido. Número considerável de empresas, algum tempo depois, em meados da década de 70, passou a adotar posturas mais dinâmicas, buscando inserir responsabilidade social à realidade de seus negócios (como passou a ocorrer na elaboração de políticas corporativas e no planejamento estratégico das empresas) conforme se vê em Wilson (apud GARGIONI, 2009, p. 25).

Já, pouco antes, no Brasil, a preocupação com a responsabilidade social teve respaldo em ações de entidades religiosas ligadas a dirigentes empresariais, como no caso da Associação de Dirigentes Cristãos de Empresas do Brasil (ADCE) cuja postura era no sentido de considerar a questão social como compromisso estratégico; incutindo-se a ideia de assunção de responsabilidade socioambiental da empresa na gestão dos seus negócios. (MORCELLI, apud GUIMARÃES, OLIVEIRA, 20017, p.103).

Em 1993, o marco da aproximação dos empresários com as ações sociais se deu por meio da Campanha Nacional da Ação da Cidadania contra a Fome, a Miséria e pela Vida, iniciativa do sociólogo Herbert de Souza, com o apoio do Pensamento Nacional das Bases Empresariais (PNBE). (GUIMARÃES, OLIVEIRA, 2017, p. 104). Em 1998, foi criado, por um grupo de empresários e executivos da iniciativa privada, o Instituto Ethos de Empresas e Responsabilidade Social que é uma Organização da Sociedade Civil de Interesse Público (Oscip) constituída como polo de organização de conhecimento, troca de experiências e desenvolvimento de ferramentas para auxiliar as empresas a refletir sobre suas gestões assumindo maior comprometimento para com a responsabilidade social e o desenvolvimento sustentável. (INSTITUTO ETHOS DE EMPRESAS E RESPONSABILIDADE SOCIAL, 2016).

Atualmente, há que se fazer a ressalva acerca da mudança da terminologia de responsabilidade social corporativa para responsabilidade social. Amplia-se o sentido do termo tornando-o comum para todas as organizações, possibilitando que cada área, segmento ou organização crie sua "própria compreensão de 


\section{Personalidade Acadêmica Homenageada: \\ Carlos Aurélio Mota de Souza (Universidade Ibirapuera - UNIB)}

responsabilidade social". (ORTOVÁ, STANKOVÁ apud GUIMARÃES, OLIVEIRA, 2017, p. 105). Especificamente, RSE é:

[...] forma de gestão que se define pela relação ética e transparente da empresa com todos os públicos com os quais ela se relaciona e pelo estabelecimento de metas empresariais compatíveis com o desenvolvimento sustentável da sociedade, preservando recursos ambientais e culturais para as gerações futuras, respeitando a diversidade e promovendo a redução das desigualdades sociais (INSTITUTO ETHOS, 2016).

José Renato Nalini (2012, p. 383), por sua vez, afirma o instituto, como sendo "[...] o plus que a empresa pode oferecer à comunidade, além do legitimo interesse de exercer uma atividade lucrativa". No mesmo sentido, Mercier apud Nalini (2012, p. 383) complementa o raciocínio ensinando que a RSE constitui-se na:

[...] integração voluntária das preocupações sociais e ecológicas das empresas às suas atividades comerciais e às relações com todas as partes envolvidas interna e externamente (acionistas, funcionários, clientes, fornecedores e parceiros, coletividades humanas), com o fim de satisfazer plenamente as obrigações jurídicas aplicáveis e investir no capital humano e no meio ambiente.

Da definição extraída do site do Instituto Ethos, verificam-se as principais características das práticas empresariais pautadas pela Responsabilidade Social. São elas: forma de gestão guiada pela ética e transparência com todas as partes interessadas; definição de metas empresariais que estejam em conformidade com o desenvolvimento sustentável e que promovam a redução das desigualdades sociais. Ainda segundo o Instituto Ethos (2006, p.11), os aspectos que caracterizam a empresa socialmente responsável encontram-se no Quadro 1 que segue. 
Personalidade Acadêmica Homenageada:

Carlos Aurélio Mota de Souza (Universidade Ibirapuera - UNIB)

Quadro 1: Características de uma empresa socialmente responsável

\begin{tabular}{|l|l|}
\hline Transparência & $\begin{array}{l}\text { Divulgando informações de maneira clara e acessível } \\
\text { a todos os públicos que se relacionam com a empresa. }\end{array}$ \\
\hline $\begin{array}{l}\text { Estabelecimento de } \\
\text { compromissos públicos }\end{array}$ & $\begin{array}{l}\text { Assumindo publicamente os compromissos que a a } \\
\text { empresa tem, sejam relacionados ao seu público } \\
\text { interno, ao futuro, à manutenção dos recursos } \\
\text { naturais, à promoção da diversidade. }\end{array}$ \\
\hline $\begin{array}{l}\text { Envolvimento com } \\
\text { instituições que } \\
\text { representam interesses } \\
\text { variados }\end{array}$ & $\begin{array}{l}\text { Procurando diálogo e contato com organizações e } \\
\text { especialistas que colaborem com a empresa para lidar } \\
\text { com seus dilemas. }\end{array}$ \\
\hline $\begin{array}{l}\text { Capacidade de atrair e e } \\
\text { manter talentos }\end{array}$ & $\begin{array}{l}\text { Apresentando-se como uma alternativa profissional } \\
\text { que possa também atender aos interesses de cidadão } \\
\text { do profissional. }\end{array}$ \\
\hline $\begin{array}{l}\text { Alto grau de motivação e e } \\
\text { comprometimento dos } \\
\text { colaboradores }\end{array}$ & $\begin{array}{l}\text { Envolvendo todos os colaboradores internos e } \\
\text { fornecedores com a gestão da RSE, demonstrando } \\
\text { coerência em seus compromissos. }\end{array}$ \\
\hline $\begin{array}{l}\text { Capacidade de lidar com } \\
\text { situações de conflito }\end{array}$ & $\begin{array}{l}\text { Demonstrando disposição para a investigação e o } \\
\text { diálogo, desenvolvendo processos que previnam } \\
\text { situações de risco, aprofundando contato com redes } \\
\text { de organizações e formadores de opinião, usando de } \\
\text { transparência nessas relações. }\end{array}$ \\
\hline $\begin{array}{l}\text { Estabelecimento de metas } \\
\text { de curto e longo prazo }\end{array}$ & $\begin{array}{l}\text { Introduzindo realmente aspectos de responsabilidade } \\
\text { social na gestão da empresa, com todas as } \\
\text { características que outros indicadores de performance } \\
\text { possuem. }\end{array}$ \\
\hline $\begin{array}{l}\text { Envolvimento da direção } \\
\text { da empresa }\end{array}$ & $\begin{array}{l}\text { Comprovando claramente o entendimento estratégico } \\
\text { que tem destas questões. Em geral, a empresa tem } \\
\text { um ou dois colaboradores que dedicam seu tempo a } \\
\text { questões de responsabilidade social. }\end{array}$ \\
\hline
\end{tabular}

Fonte: Adaptado de Instituto Ethos (2006)

Importante, pois, ressaltar que a RSE ainda que não tenha disciplina legal específica ${ }^{2}$ no Ordenamento Jurídico brasileiro, deve guardar relação harmoniosa com o Direito, conforme ressaltam Guimarães e Oliveira (2017, p. 105): "a

\footnotetext{
2 Já se tentou regular a matéria por meio do Projeto de Lei (PL) 1305/2003. Ainda convém mencionar a Lei $n^{\circ} 13.303 / 2016$ que, em certa medida, aborda o tema ao estabelecer, no art. $27, \S 2^{\circ}$, que a empresa pública e a sociedade de economia mista deverão, nos termos da lei, adotar práticas de sustentabilidade ambiental e de responsabilidade social corporativa compatíveis com o mercado em que atuam. Já o Projeto de Lei $n^{\circ}$ 8.224/17 pretende criar o Selo Empresa Cidadã, com o objetivo de atestar a responsabilidade social e ambiental das empresas brasileiras. Tem-se, ainda, como norma, de ordem técnica e não jurídica sobre o tema, a ISO 26.000.
} 


\section{Personalidade Acadêmica Homenageada:}

Carlos Aurélio Mota de Souza (Universidade Ibirapuera - UNIB)

responsabilidade social das empresas diz respeito ao compromisso com a legalidade e com as necessidades da comunidade pensadas em termos de melhoria das condições de vida de todos". Bessa apud Guimarães e Oliveira (2017, p. 105) ainda afirma "[...] que a responsabilidade social das empresas contempla um agir de acordo com o direito, com a função social da empresa e com os princípios de direito privado, considerado o contexto do interesse público envolvido".

Duas são as vertentes para o entendimento do tema; é o que se passa a tratar.

\subsection{AS VERTENTES DOUTRINÁRIAS SOBRE A RSE.}

As principais vertentes teóricas acerca do instituto da RSE são: a um; o entendimento defendendo que a RSE deve consistir-se unicamente na prática de maximização do lucro, gerando mais emprego, renda, eficiência econômica e consequentemente bem estar social e; a dois, o posicionamento defendendo que a empresa deve ir além do objetivo de maximização de lucros, desenvolvendo práticas que beneficiem todas as partes interessadas: trabalhadores, acionistas, consumidores, comunidade próximas, entre outros.

Embora seja necessário à sobrevivência das empresas, o lucro não necessariamente deve ser o único objetivo a ser perseguido. É o que acreditam os defensores da RSE. Gonçalves e Guimarães (2010, p. 31) comentam que, frequentemente, empresas tomam decisões que, aparentemente, não implicariam em maximizar o lucro, a fim de; por exemplo, estabelecer uma reputação socialmente inclusora de longo prazo; ou ampliar a fatia de mercado vendendo a um preço baixo por certo tempo; ou ajudar a preservar o meio ambiente. Porém, recordam que o objetivo de se obter lucro não pode ser totalmente ignorado, pois empresas que não buscam maximizar seu lucro não sobrevivem por muito tempo, ou seja, não é possível afastar-se de tal objetivo por muito tempo sob pena de fechamento da empresa. Portanto, seja por uma ou outra tendência doutrinária, fato é que a empresa interage com a sociedade na qual se encontra de forma que, perseguindo direta e inexoravelmente seu objetivo primordial de lucro ou optando, espontaneamente, por redistribuição direta de renda na forma de inclusão social ou preservação ambiental; 


\section{Personalidade Acadêmica Homenageada:}

Carlos Aurélio Mota de Souza (Universidade Ibirapuera - UNIB)

incorrerá, ainda que, em objetivo de segundo plano, na realização de ação com reflexos socioambientais que poderão, sim, ser mais ou menos efetivos, eficazes e, mesmo eficientes para que se atinjam os desideratos empresariais, sociais e ambientais. As escolhas empresariais tratam de verdadeiros tradeoffs sociais com indeléveis reflexos ambientais.

Para Karkotli (2006, p.60), a atuação organizacional com responsabilidade social pressupõe a necessidade de participação para que se alcance o derradeiro desenvolvimento com sustentabilidade nas dimensões econômica, social e ambiental; entretanto, tais ações podem ser usadas como subterfúgios para se aumentar o lucro, via estratégia de marketing. Com a finalidade de esclarecer as diferenças entre o que seria ação filantrópica, marketing ou responsabilidade social, veja-se o Quadro 2 a seguir:

Quadro 2: Definições da área social

\begin{tabular}{|l|l|}
\hline Filantropia & $\begin{array}{l}\text { Tem como base os princípios da caridade e da custódia e amor à } \\
\text { humanidade. }\end{array}$ \\
\hline Ação Social & $\begin{array}{l}\text { É ação de curto prazo com objetivo de satisfazer as necessidades } \\
\text { em prol da sociedade ou de uma comunidade específica. }\end{array}$ \\
\hline $\begin{array}{l}\text { Responsabilida } \\
\text { de Social } \\
\text { Corporativa }\end{array}$ & $\begin{array}{l}\text { É comportamento ético e responsável na busca de qualidade } \\
\text { nas relações que a organização estabelece com todos os seus } \\
\text { stakeholders, associado direta e indiretamente ao negócio da } \\
\text { empresa, incorporado à orientação estratégica da empresa e } \\
\text { refletido em desafios éticos para as dimensões econômicas, } \\
\text { ambiental e social. }\end{array}$ \\
\hline $\begin{array}{l}\text { Marketing } \\
\text { Social }\end{array}$ & $\begin{array}{l}\text { Significa entender e atender a sociedade, proporcionando a } \\
\text { satisfação e o bem-estar da mesma dentro de um comportamento } \\
\text { ético e social responsável, visando às transformações sociais. }\end{array}$ \\
\hline $\begin{array}{l}\text { Marketing } \\
\text { ldeológico/ } \\
\text { Institucional }\end{array}$ & $\begin{array}{l}\text { É utilizado para indicar e associar as iniciativas pelas quais uma } \\
\text { empresa procura manter, fortalecer e solidificar a imagem da } \\
\text { marca e a identidade da marca perante o seu público - alvo. }\end{array}$ \\
\hline
\end{tabular}

Fonte: Karkotli (2006, p.63)

Segundo se vê como conceito de Responsabilidade Social Corporativa, não se visualiza, em nenhum momento, questões de ordem legal. Todavia, ao se tratar de uma "busca de qualidade nas relações [...]", fica claro que não é obrigação, pois é opção de uma empresa buscar ou não de forma ética e responsável (e não legal) uma 


\section{Personalidade Acadêmica Homenageada:}

Carlos Aurélio Mota de Souza (Universidade Ibirapuera - UNIB)

melhoria na qualidade de relações com seus stakeholders, e incorporar ou não tal busca em suas estratégias empresariais. É ato voluntário.

A fim de reduzir as incertezas a respeito da atuação das empresas com RSE, o "Balanço Social" é um dos indicadores mais conhecidos, além da "Demonstração do Valor Adicionado" e as "Certificações de Responsabilidade Social” (TENÓRIO, 2004, p.37). Sem serem, estas, exigências legais; diversas empresas têm adotado tais demonstrações, ou empenham-se em obter aquelas certificações em função de atingirem patamar de atuação econômico-social inclusora, progressista e com derradeira preocupação socioambiental. Em Silva et al (2012, p. pp.72-86) pode-se ver estudo a respeito da certificação do Instituto Brasileiro de Análises Sociais e Econômicas (IBASE), concluindo que as empresas que receberam o selo IBASE utilizaram mais indicadores sociais voltados para demonstrar a relação daquelas entidades, primeiramente, com os seus próprios recursos humanos, seguindo com ações voltadas para a sociedade e, por último, em defesa do meio ambiente. Reconhecendo a relevância do tema, em 01/11/2010 foi publicada a norma internacional ISO 26.000 tratando sobre as Diretrizes sobre Responsabilidade Social e, logo em seguida, no Brasil, em 08/12/2010 foi publicada a norma ABNT NBR ISO 26.000 .

Segundo a ISO 26.000, a responsabilidade social se expressa pelo desejo e pelo propósito das organizações em incorporarem considerações socioambientais em seus processos decisórios e a responsabilizarem-se pelos impactos de suas decisões e atividades na sociedade e no meio ambiente. (INMETRO, 2012). McWilliams e Siegel (2001, p.2) afirmam que os conceitos de responsabilidade social corporativa nem sempre são claros; porém entendem que RSE significa ir além do legalmente exigido. No Instituto Ethos (2006, p.7), "RSE está além do que a empresa deve fazer por obrigação legal. Cumprir a lei não faz uma empresa ser socialmente responsável".

Ainda se destaque que Carroll (1979, pp. 497-505) define a responsabilidade social envolvendo quatro dimensões: responsabilidades discricionárias, responsabilidades éticas, responsabilidades legais e responsabilidades econômicas, lembrando que tais dimensões não são mutuamente excludentes, tampouco cumulativas e/ou aditivas. 


\section{Personalidade Acadêmica Homenageada:}

Carlos Aurélio Mota de Souza (Universidade Ibirapuera - UNIB)

Ao que se vê; seja, conforme entendimento de que realizando exclusivamente seu objetivo principal, em Sistema Capitalista de Mercado, a empresa alcança (de forma utilitária) resultados sociais; seja pela visão progressista de que, via ações próprias da RSE, conforme Quadro 1 acima, a ação empresarial em sociedade tem dois objetivos em especial, a saber: a um, a primazia para o bem-estar humano (fim de qualquer ação seja do público interno ou externo à empresa) e; a dois, a proteção para uma vida perene da espécie humana.

\section{PRAGMÁTICA EMPRESARIAL: LUCROS OU RESPONSABILIDADE SOCIOAMBIENTAL (RSAE)?}

A Ciência Econômica ortodoxa considera que o objetivo das empresas é maximizar o lucro; embora necessário para sua sobrevivência, o lucro não necessariamente deve ser o único objetivo empresarial a ser perseguido. É o que acreditam os defensores da Responsabilidade Socioambiental da Empresa (RSAE). Se produzir para atender a demanda dos consumidores é o objetivo de um empreendimento lucrativo que reúne os fatores de produção (natureza, capital, trabalho, iniciativa empresarial e tecnologia); por outro lado, inserido em contexto de muita fragilidade socioambiental, tal agente econômico não pode descuidar de sua inexorável responsabilidade socioambiental para com seus públicos externo e interno. Em um Sistema Capitalista de mercado, para sobreviver, as empresas precisam ser lucrativas; porém, para além da maximização de lucros a chamada RSAE deve e, defende-se, que está orientando a tomada de decisão de número crescente de empresas, inclusive, brasileiras, preocupadas com o bem-estar social e com a sustentabilidade. Segundo Tupy $(2008,74)$, no Brasil, "o número de empresas preocupadas com a questão socioambiental cresce consideravelmente", informando que, segundo pesquisas, $67 \%$ das empresas da região Sudeste, $55 \%$ do Nordeste e $46 \%$ do Sul do País realizaram alguma atividade não obrigatória ligada à comunidade ou aos seus funcionários. Tais números demonstram que, embora se defenda a 


\section{Personalidade Acadêmica Homenageada:}

Carlos Aurélio Mota de Souza (Universidade Ibirapuera - UNIB)

maximização de lucros como único objetivo das empresas, tem crescido os defensores da RSAE.

Agir com RSAE implica a ideia de que as organizações empresariais têm obrigações sociais e; logo, não devem pensar unicamente na obtenção de lucros. Embora se possa, a princípio, pensar que quando dada empresa investe com responsabilidade socioambiental reduz seu lucro, ou piora sua saúde econômicofinanceira. Estudos recentes têm demonstrado que o engajamento social provoca o efeito contrário, tal como em Briguenti, Souza e Hein (2014, p. 11) e Grellmann et al (2017, p. 12). Neste último estudo constatou-se que, de forma global, os investimentos em atitudes voltadas para ações com responsabilidade socioambiental corporativa impulsionam maior destaque para a empresa perante seus investidores, clientes, fornecedores e sociedade em geral e, como consequência, levam ao aumento da rentabilidade financeira da própria empresa. Neste sentido, Laan, Ees e Witteloostuijn (2008, pp. 308) chegaram à conclusão de que o efeito no desempenho financeiro de uma boa reputação social é menor que o impacto de uma má reputação de igual magnitude. Também nesta direção o estudo de Sousa et al (2011, p. 52) mostrou que, um ano após o ingresso das empresas na carteira do Índice de Sustentabilidade Empresarial da BMF Bovespa, em 2007, suas receitas líquidas aumentaram 56,46\% em relação ao ano anterior. Soma-se a esse dado o estudo de Mota (2009, pp. 103), no qual os resultados indicaram que "a responsabilidade social antecede a percepção de justiça de preço, gerando impactos fortes e positivos no valor percebido, na satisfação e nas intenções de compra". Embora tais resultados não sejam unânimes, evidenciam que, quando uma empresa age com responsabilidade socioambiental, além de contribuir com o bem estar social, não necessariamente afasta a empresa de seu objetivo de maximizar seus lucros. Por esta razão, empresas podem estar valendo-se desta constatação para sinalizar à sociedade que atuam com responsabilidade socioambiental. Destarte, ainda que pelo egoísmo próprio da obtenção do lucro, ações para a inclusão social, por parte dos gestores das empresas, podem ser ótimas como fator estratégico de alavancamento empresarial; bem como, para a inclusão social. Exemplos de práticas de RSAE são evidenciados em projetos sociais respaldados pelas leis de incentivo brasileiras, tais como as Leis de Incentivo 


\title{
Personalidade Acadêmica Homenageada:
}

Carlos Aurélio Mota de Souza (Universidade Ibirapuera - UNIB)

à Cultura; para favorecimento dos trabalhadores, voltadas para a flexibilização de jornadas de trabalho; incentivadoras da criação de creches para filhos de trabalhadores; defensoras da preservação do meio ambiente etc.

Entende-se, pois, que deve ser superada a defesa de teorias que excluem a RSAE em vista do único objetivo de maximização do lucro excludente do outro, portanto, não altero; destarte, defendendo-se que a empresa pode gerar mais emprego, renda, eficiência econômica e consequentemente bem estar social; simplesmente, agindo para além do objetivo de maximização de lucros, desenvolvendo práticas que beneficiem todas as partes interessadas: trabalhadores, acionistas, consumidores, comunidade próximas, entre outros. A RSAE pode, então, ser percebida sob o enfoque do Princípio da Eficiência Econômico-Social (PEES) a partir da Análise Econômica do Direito (AED).

Machado e Machado (2011, p. 20) verificaram 237 empresas de 15 setores econômicos por cinco anos, a fim de descobrir se a responsabilidade socioambiental, representada pelos indicadores sociais e ambientais, líquidos de encargos sociais compulsórios e tributos, causava impacto no desempenho financeiro das empresas, no caso, na receita líquida:

\begin{abstract}
Por fim, os resultados apontam haver um impacto positivo da responsabilidade social no desempenho financeiro das empresas, no que tange aos indicadores internos e externos, não se podendo rejeitar as hipóteses 1 e 2 da pesquisa. Quanto à responsabilidade representada pelos indicadores ambientais, não há indícios de que podem acarretar impactos, positivos ou negativos, no desempenho financeiro das empresas estudas, rejeitando-se, assim, a hipótese 3 da pesquisa.
\end{abstract}

Tupy (2008) analisou o desempenho econômico - financeiro de empresas cujas ações compõem diferentes índices das Bolsas de Valores Brasileiras, um deles composto por ações de empresas com práticas sociais e de preservação ambiental, as quais compõem o Índice de Sustentabilidade Empresarial (ISE) e outro, por empresas que não se enquadram nos critérios de seleção sobre práticas sociais e ambientais. Não foram encontrados resultados estatisticamente significativos relacionando 
Personalidade Acadêmica Homenageada:

Carlos Aurélio Mota de Souza (Universidade Ibirapuera - UNIB)

variáveis econômico-financeiras e socioambientais. Tonnoli, Rover e Ferreira (2017) elaboraram Quadro 3 com resultados de pesquisas semelhantes, segundo se vê:

Quadro 3: Estudos anteriores sobre RSE

\begin{tabular}{|c|c|}
\hline $\begin{array}{l}\text { Estudos an- } \\
\text { teriores Au- } \\
\text { tor (es) /ano }\end{array}$ & Estudo \\
\hline $\begin{array}{l}\text { Bertagnolli, } \\
\text { Ott e } \\
\text { Damacena } \\
(2006)\end{array}$ & $\begin{array}{l}\text { Os autores determinaram a influência dos investimentos socioambi- } \\
\text { entais no desempenho econômico das empresas. Utilizaram balan- } \\
\text { ços sociais de } 176 \text { empresas (IBASE) e indicadores sociais internos } \\
\text { e externos e indicadores ambientais (variáveis independentes) e a } \\
\text { receita líquida e resultado operacional (variáveis dependentes) e } \\
\text { constataram que os investimentos explicam alterações nas variá- } \\
\text { veis dependentes. }\end{array}$ \\
\hline $\begin{array}{l}\text { Macedo, } \\
\text { Souza, Souza } \\
\text { e Cipola, } \\
(2007)\end{array}$ & $\begin{array}{l}\text { Os pesquisadores avaliaram a performance das empresas do ISE } \\
\text { por meio de indicadores de liquidez, endividamento e lucratividade } \\
\text { entre empresas da Revista Melhores e Maiores e compararam as } \\
\text { que pertencem ao ISE com as demais. Os autores concluíram não } \\
\text { haver vantagens significativas das empresas socialmente respon- } \\
\text { sáveis sobre o mercado. }\end{array}$ \\
\hline $\begin{array}{l}\text { Ott, Alves e } \\
\text { Flores (2009) }\end{array}$ & $\begin{array}{l}\text { Os autores replicaram a metodologia de Bertagnolli et al. (2006) e } \\
\text { analisaram investimentos ambientais e desempenho econômico } \\
\text { das empresas com uma amostra composta por } 353 \text { companhias, e } \\
\text { apresentaram resultados semelhantes ao da pesquisa de } 2006 \text {. }\end{array}$ \\
\hline Nunes (2010) & $\begin{array}{l}\text { Foram analisadas as variáveis (tamanho, setor de atividade, con- } \\
\text { centração acionária, localização do controle acionário, ser emissora } \\
\text { de ADR e ser de propriedade estatal) de } 124 \text { empresas que levaram } \\
\text { a adesão ao ISE. Concluíram que o tamanho da empresa e setor de } \\
\text { atividade interferiram na entrada ao ISE. }\end{array}$ \\
\hline $\begin{array}{l}\text { Guimarães } \\
\text { (2010) }\end{array}$ & $\begin{array}{l}\text { O autor avaliou se a passagem das companhias pelo ISE influencia } \\
\text { o valor da empresa em longo prazo. Os resultados não confirmaram } \\
\text { o aumento do valor das empresas. }\end{array}$ \\
\hline $\begin{array}{l}\text { Machado, Ma- } \\
\text { cedo, } \\
\text { Machado e Si- } \\
\text { queira (2012) }\end{array}$ & $\begin{array}{l}\text { Investigaram a relação entre investimentos socioambientais e a in- } \\
\text { clusão de empresa ao ISE por meio de regressão logística e, con- } \\
\text { clúram que houve relação positiva entre eles, demonstrando com- } \\
\text { prometimento da empresa com a sustentabilidade. }\end{array}$ \\
\hline $\begin{array}{l}\text { Garcia e Or- } \\
\text { sato }(2013)\end{array}$ & $\begin{array}{l}\text { Pesquisaram } 15 \text { trabalhos acadêmicos com diversos métodos de } \\
\text { avaliação econômico-financeira ente } 2006 \text { e } 2011 \text {, verificando a cri- } \\
\text { ação de valor para as empresas que compuseram o ISE. Os autores } \\
\text { não encontraram diferenças expressivas entre o fato da empresa } \\
\text { aderir ao índice e o impacto no valor de suas ações. }\end{array}$ \\
\hline
\end{tabular}

Fonte: Tonnoli, Rover e Ferreira (2017). 


\title{
Personalidade Acadêmica Homenageada:
}

Carlos Aurélio Mota de Souza (Universidade Ibirapuera - UNIB)

Tupy (2008) esclarece que "os resultados dos estudos sobre relações entre investimentos em meio-ambiente e responsabilidade social e desempenho econômico-financeiro de empresas são controvertidos". Corroboram, assim, Machado e Machado (2011):

\begin{abstract}
Observam-se, também, como resultados dos estudos, relações positivas, negativas e neutras entre desempenho social e financeiro. Pava e Krausz (1996) revisaram 21 estudos, no período de 1972 a 1992. Em 12 deles, foi encontrada uma relação positiva, enquanto que somente em um caso foi encontrada uma relação negativa. Nos oito estudos restantes, os resultados mostraram-se neutros. Evidências semelhantes foram observadas por Beurden e Gossling (2008), onde 68\% dos artigos investigados apresentaram relação positiva, $6 \%$ relação negativa e $26 \%$ nenhuma relação significante.
\end{abstract}

Embora os resultados difiram, é possível observar que percentual bastante reduzido de resultados encontrou relação negativa. Este resultado (negativo) explica o receio dos empresários em investir em responsabilidade socioambiental, vez que tal investimento seria apenas custo, sem contrapartida financeira que fosse suficiente para evitar piora na saúde econômico-financeira da empresa. Nesta direção encontrase o estudo de Brammer, Brooks e Pavelin (2006) e López, Garcia e Rodriguez (2007).

Em direção oposta, os resultados positivos, como os encontrados por Simpson e Kohers (2002), foram, por eles, explicados devido ao fato de que os custos com responsabilidade social eram mínimos em relação aos benefícios gerados para a empresa. Resultados positivos foram encontrados em Briguenti, Souza e Hein (2014) e Grellmann et al (2017). Neste último estudo constatou-se que, forma global, os investimentos em atitudes voltadas a ações de responsabilidade social corporativa impulsionam maior destaque para a empresa perante aos investidores, clientes, fornecedores e sociedade, e como consequência levam ao aumento da rentabilidade financeira da empresa. Laan, Ees e Witteloostuijn (2008) a sua vez, chegaram à conclusão de que o efeito no desempenho financeiro de uma boa reputação social é menor que o impacto de uma má reputação de igual magnitude.

Em que pesem os citados posicionamentos: lucrar para, ao fim, contribuir socialmente ou; contribuir socialmente, para, derradeiramente, lucrar; resta relacionar a vertente que se mostra mais compatível com as exigências atuais da sociedade 
Personalidade Acadêmica Homenageada:

Carlos Aurélio Mota de Souza (Universidade Ibirapuera - UNIB)

segundo o que já se definiu como Mínimo Ético Legal (MEL) e como Princípio da Eficiência Econômica Social (PEES).

\section{A ANÁLISE ECONÔMICA DO DIREITO (AED) E O PRINCÍPIO DA EFICIÊNCIA ECONÔMICO-SOCIAL (PEES) PARA A EFETIVAÇÃO DA RESPONSABILIDADE SOCIOAMBIENTAL DA EMPRESA (RSAE)}

As Economic Schools próprias da Análise Econômica do Direito (AED), com visão econômico-jurídica, surgiram a partir dos estudos pioneiros de autores como Ronald Coase (1960), Guido Calabresi (1961) e Richard Allen Posner (1973 e 2007). Entende-se, pois, que o método analítico-interpretativo-construtivista da AED torna o Direito consequencialista e jurídico-persuasivo esgotando o paradigma jurídicocoercitivo vigente e determinando o comportamento social segundo análise da relação de custo e benefício. Assim, a prática jurídico-econômica de mercado-social deve refletir fenômeno jurídico-social conforme realidade inarredável da previsão legal segundo critérios racional-normativos de maximização de lucros - riqueza - e de eficiência econômica que ocorram dentro de dialética social-econômico-normativa inclusiva e progressista, ainda conforme ao que se defende como Mínimo Ético Legal (MEL) e segundo o PEES.

Como postulados da AED defendem-se: a um, o individualismo metodológico, segundo a racionalidade maximizadora economicista; a dois, necessária harmonia entre as normas jurídicas e as leis econômicas e; a três, o paradigma jurídico deve volver-se para a agilização e fluidez das relações de produção, maximização dos lucros e otimização da produção e utilização da riqueza individual e social; ao que se acrescenta a necessidade de ação inclusora e responsável social e ambientalmente. É nessa perspectiva de reflexão que se discute o papel do Estado e do Direito para resolução de controvérsias segundo (re) distribuição de renda e alocação de recursos a partir de tomada de decisão racional consideradora do social sob a égide do PEES, ampliando a riqueza, porém, sem descuidar da necessária inclusão social como forma ideal de eliminação das externalidades negativas. 


\section{Personalidade Acadêmica Homenageada:}

Carlos Aurélio Mota de Souza (Universidade Ibirapuera - UNIB)

A doutrina econômica conhece eficiência conforme a melhoria de Pareto, o ótimo de Pareto e o critério de compensação potencial de Kaldor-Hicks. Para além dos conceitos de eficiência produtiva, alocativa e de escopo, entende-se, o PEES segundo maximização de resultados esperados quando da adjudicação de direitos ou da determinação de obrigações, conforme caráter recíproco das ações e interesses, porém, considerando o reflexo social e o custo externo imposto à sociedade presente; ou mesmo, futura, de forma a serem compensados, na totalidade, os prejuízos impostos pelo ganho presente das partes envolvidas. O PEES considera, no cálculo econométrico, as variáveis de cunho social e temporal que, corretamente valoradas, devem ser internalizadas de forma que a relação de custo e benefício demonstre a realidade das utilidades auferidas quando se sacrificando determinados bens e serviços de outrem; considerado o maior número ou a totalidade dos agentes envolvidos. Observa-se que, para o PEES, o altruísmo não está descartado, mesmo em termos econômicos, segundo derivação de utilidade, por parte de alguém, em relação à utilidade desejada por outrem, conforme a satisfação do próximo.

A aproximação entre o Direito e a Teoria Econômica torna-se possível segundo aplicação do PEES, dadas as restrições materiais, segundo se almeje a equiparação dos níveis de satisfação individuais e coletivos envolvidos no caso concreto, ainda, difundindo-se incentivos para a ação socialmente desejada ou obstáculos para atos condenáveis. Nesse sentido, de ação balizada pelo MEL e perseguindo os objetivos do PEES é que se deve pensar a RSE conforme se perceba que hão de serem superados os egoísmos individuais. Já se disse:

[...] a humanidade cresce globalmente e, a transitoriedade da vida individual não representa, nem justifica o isolacionismo doentio do poder ineficiente, egoísta, despótico e descomprometido com a própria sobrevivência e a dos demais componentes da humanidade; assim como, não justifica a ganância que desconsidera o social; nem a inércia que aumenta o fardo do próximo. Muito menos, justifica-se a destruição do suporte material da vida na Terra, uma vez que se entende, dentro de perspectiva progressista e includente, ser, a riqueza social, individualmente apropriada, porém, e sempre, segundo o eficiente uso comprometido pelo PEES. É nesta perspectiva de reflexão que se discute o papel do Estado, do Direito e do mercado. (Gonçalves e Stelzer, 2014). 


\section{Personalidade Acadêmica Homenageada:}

Carlos Aurélio Mota de Souza (Universidade Ibirapuera - UNIB)

A RSAE implica, em função do PEES, em buscar-se atuação empresarial adequada para a obtenção de máxima felicidade de todos os envolvidos no empreendimento (interna e externamente), segundo perspectiva social e economicamente inclusora, (re) distribuição progressista dos escassos recursos e ação empresarial que vise o lucro que, sendo privado, não pode desconsiderar o uso da riqueza social. A tomada de decisão econômico-jurídica segundo o PEES deve levar em consideração: a um, a inclusão do maior número de variáveis no cálculo econométrico de custo e benefício; a dois, a consideração; para fins de cálculo e distribuição de benefícios ou imposição de custos - adjudicação de direitos, da totalidade dos agentes econômicos e das partes envolvidas, ou que venham a sofrer reflexos em virtude da tomada de decisão econômico-jurídica; a três, o primado da distribuição e redistribuição dos escassos recursos em função da eficiência econômico-social, segundo o MEL determinado pelo Estado; a quatro, a eliminação dos reflexos das externalidades individuais ou coletivas que venham a determinar injustificáveis custos sociais, bem como, os reflexos da ação presente com relação às gerações futuras e; a cinco, a avaliação dos resultados da ação em sociedade a partir da consideração dos incentivos indutores ou obstantes da ação social

\section{CONCLUSÃO}

Buscou-se, no presente texto, tratar sobre a RSAE; destarte, após apreciação gráfico-econômica a respeito da maximização de lucros, mormente, em concorrência monopolística, destacou-se que, em um primeiro momento, a RSAE implica aumento de custos. Apresentou-se o histórico, conceito e principais características da RSE, bem como, suas duas principais vertentes doutrinárias. Ao final, explanou-se sobre RSAE sob o enfoque da AED e do PEES para a efetivação da primeira. Entendeu-se que quando, na empresa, se adotam práticas de responsabilidade socioambiental, os lucros podem elevar-se, dependendo do quanto as receitas se alterarão em relação aos custos, e considerando a atitude de se produzir em nível maximizador de lucros. Estudos recentes demonstraram que 0 engajamento das empresas em 


\section{Personalidade Acadêmica Homenageada:}

Carlos Aurélio Mota de Souza (Universidade Ibirapuera - UNIB)

responsabilidade socioambiental produz resultados financeiros positivos; porém as conclusões acerca desta evidência ainda são controversas. Ainda assim, a maior parte dos estudos aponta para relação positiva ou neutra em relação ao investimento socioambiental impactar o desempenho econômico - financeiro das empresas.

A RSE implicando, também, responsabilidade ambiental (RSAE) vem ganhando visibilidade na busca, pelas empresas, de práticas condizentes com o desenvolvimento sustentável e social. Assim, a RSE pode, para os mais utilitários, advir da ação empresarial em perseguir objetiva e inexoravelmente o lucro em mercado, seu fim precípuo; ou, de outra forma, obter, o lucro, segundo práxis socialmente inclusiva que, por fim, há de implicar em resultado inclusor e progressista. Passou-se, ato contínuo, à explanação do Princípio da Eficiência Econômico-Social (PEES) para, então, relacioná-lo com o tema da RSAE. Defendeu-se, pois, que a RSAE, para além de simples prática decorrente da norma, deve representar ação empresarial socialmente inclusora, que vise ao resultado de lucro obtido segundo (re) distribuição social durante o processo produtivo atingindo os públicos internos e externos, presentes e futuros da empresa. Destarte, garante-se, equilíbrio econômicojurídico e cuidado socioambiental, mormente, conforme ação embasada no PEES segundo possível acomodação, nos termos de práxis ideológico-normativa, entre os fins racionais economicistas da ação empresarial e a necessidade elementar de equidade - oportunidades: em recursos, emprego, educação, bem-estar social mínimo. A RSAE, segundo o PEES e o MEL, condena o direito individualista, voltado para o uso exclusivo da propriedade, segundo partilha social da riqueza. Nesse sentido, é necessária a reforma íntima da vontade racional dos indivíduos em busca da RSAE e da alteridade. Assim, no egoísmo da tomada de decisões de forma racional e eficiente resta, para o Planeta habitado, a lógica de exploração social dos recursos para usos eficientes. A "utopia capitalista" é o caminho que se apresenta possível para a união dos egoísmos individuais, pelo fato do homem ter como imprescindível sua sobrevivência, levando-o a convencer os demais da inexorabilidade da ação conjunta sob pena do total extermínio; restando, por consequência da busca do bem-estar de uns, a salvação e segurança de outros. Não há mais espaço para o isolamento e, 
Personalidade Acadêmica Homenageada:

Carlos Aurélio Mota de Souza (Universidade Ibirapuera - UNIB)

neste contexto, necessário é o repensar da ação empresarial satisfazendo, por fim, os anseios individuais e sociais.

A RSE, segundo o PEES, implica exercer a atividade econômica empresarial em estado de mercado-social compatibilizando-se, em termos de práxis ideológiconormativa, os fins racionais economicistas da ação empresarial em busca do lucro e a necessidade elementar de equidade no âmbito jurídico, de fraternidade no âmbito econômico, de liberdade política e de inclusão social, uma vez adotado o apropriar individual racional - uso eficiente dos recursos e relevadas as consequências sociais - externalidades. A ação empresarial orientada pela RSAE cria, disciplina e aplica a riqueza segundo o apropriar e o usar da riqueza social, individualmente apropriada, em sociedade, ainda, lembrando-se que, o homem, sendo mais que seus desejos materiais, é ser espiritual e social que necessita da sociedade para, assim, usufruir com plena intensidade o seu direito de vida.

\section{REFERÊNCIAS}

BERTONCELLO, Silvio Luiz Tadeu; JÚNIOR, João Chang. A importância da Responsabilidade Social Corporativa Como Fator de Diferenciação. FACOM, n. 17. 2007.

BRAMMER, S.; BROOKS, C; PAVELIN, S. Corporate social performance and stock returns: UK evidence from disaggregate measures. Jan. 2006. Disponível em: <http://centaur.reading.ac.uk/20507/1/20507.pdf> Acesso em 08/08/2018.

BRIGHENTI, Josiane; SOUZA, Taciana Rodrigues de; HEIN, Nelson. Investimentos Ambientais e Desempenho Econômico-Financeiro das Empresas Brasileiras Pertencentes ao Índice de Sustentabilidade Empresarial - ISE. In: XVI ENGEMA. Anais. Disponível em: <http://www.engema.org.br/XVIENGEMA/120.pdf>. Acesso em 08/08/2018.

CARROL, Archie B. A three dimensional conceptual model of corporate performance. Academy of Management Review. Vol. 4. N.4. 1979. Disponível em: $<$ https://www.jstor.org/stable/pdf/257850.pdf?refreqid=excel-

sior\%3Aa84294ddd7b5a832cb7e34cc34daa389> Acesso em: 08/08/2018.

CALABRESI, Guido. Some Thoughts on Risk Distribution and the law of Torts. V. 70 Yale Law Journal. p. 499, 1961. 
Personalidade Acadêmica Homenageada:

Carlos Aurélio Mota de Souza (Universidade Ibirapuera - UNIB)

COASE, Ronald H. The Problem of Social Cost. The Journal of Law and Economics. V. 3, p. 1. 1960. pp.1-44.

COOTER, Robert D. e ULEN, Thomas. Law and Economics. Harper Collins Publishers, 1988.

GARGIONI, Paula da Costa. Marco conceitual para a responsabilidade corporativa. Florianópolis, 2009. 278 f. Dissertação (Mestrado) - Universidade Federal de Santa Catarina, Centro Tecnológico, Programa de Pós-Graduação em Engenharia de Produção, Florianópolis, 2009.

GONÇALVES, Carlos Eduardo. GUIMARÃES, Bernardo. Introdução à Economia. Rio de Janeiro: Elsevier, 2010.

GONÇALVES, Everton das Neves e STELZER, Joana. O Princípio da Eficiência Econômico-Social no Direito Brasileiro: a tomada de decisão normativo-judicial. In: Sequencia. V. 35, n. 68. Florianópolis, SC. 2014. Pp. 261-290. ISSN 2177-7055. Doi: http://dx.doi.org/10.5007/2177-7055.2013v35n68p261. Disponível em $<$ https://periodicos.ufsc.br/index.php/sequencia/article/view/21777055.2013v35n68p261>. Acesso em 08/08/2018.

GRELLMANN, Aline Bonfada et al. Análise da Rentabilidade das Empresas Listadas no Índice de Sustentabilidade Empresarial em Relação as Empresas Listadas na BMFBovespa. In: XIX ENGEMA. Anais... Disponível em: <http://engemausp.submissao.com.br/19/anais/arquivos/49.pdf> Acesso em: 08/08/2018.

GUIMARÃES, Fernanda Pereira Macedo; OLIVEIRA, Francisco Cardozo. Responsabilidade social das empresas e sua relevância para a evolução social na perspectiva da realidade brasileira. In: Revista Brasileira de Direito Empresarial. v. $3, \quad$ n. $2, \quad$ jul-dez $2017 . \quad$ Disponível em: $<$ http://www.indexlaw.org/index.php/direitoempresarial/article/view/3776>. Acesso em 08/08/2018.

INSTITUTO ETHOS. Conceitos Básicos e Indicadores de Responsabilidade Social Empresarial. 2007. Disponível em: <https://www3.ethos.org.br/wpcontent/uploads/2014/05/Conc Bas e Indic de Respon Soc Empres 5edi.pdf>. Acesso em: 08/08/2018.

INMETRO.

ISO

26000.

Disponível

em:

$<$ http://www.inmetro.gov.br/qualidade/responsabilidade_social/iso26000.asp>. Acesso em: 08/08/2018.

KARKOTLI, Gilson. Responsabilidade Social Empresarial. Petrópolis: Vozes, 2006. 
Personalidade Acadêmica Homenageada:

Carlos Aurélio Mota de Souza (Universidade Ibirapuera - UNIB)

LAAN, Gerwin Van Der.; EES, Hans Van; WITTELOOSTUIJN, Arjen Van. Corporate social and financial performance: an extended stakeholder theory, and empirical test with accounting measures. Journal of Business Ethics, v.79, p.299-310, 2008. Disponível em: <https://link.springer.com/article/10.1007/s10551-007-9398-0>. Acesso em: 08/08/2018.

LÓPEZ, M. V.; GARCIA, A.; RODRIGUEZ, L. Sustainable development and corporate performance: a study based on the Dow Jones Sustainability Index. Journal of Business Ethics, v.75, p. 285-300, 2007. Disponível em: <https://link.springer.com/article/10.1007/s10551-006-9253-8>. Acesso em: 08/08/2018.

MACEDO, Marcelo Álvaro da Silva et al. Desempenho de empresas socialmente responsáveis: uma análise por índices contábil-financeiros. In: Revista Produção Online. Florianópolis, Edição especial, 2007.

MACHADO, Márcio André Veras; MACHADO, Márcia Reis. Responsabilidade Social Impacta o Desempenho Financeiro das Empresas? Advances in Scientific and Applied Accounting. São Paulo, v.4, n.1, p.2-23, 2011.

McWILLIAMS, Abagail; SIEGEL, Donald. Corporate Social Responsibility: A Theory of the Firm Perspective. The Academy of Management Review. Vol. 26. N.1. p117-127. 2001. Disponível em: <http://www.jstor.org/stable/259398>. Acesso em: 08/08/2018.

MOTA, Marcio De Oliveira, LIMA, Renata Carneiro; FREITAS, Ana Augusta. A Responsabilidade Social à Luz da Justiça de Preço. In: Revista de Administração FACES Journal, v.8 (3), 2009. Disponível em $<$ http://www.fumec.br/revistas/facesp/article/view/158/155>. Acesso em 08/08/2018.

NALINI, José Renato. Ética Geral e Profissional. 9 ed. rev. atual. ampl. São Paulo: Editora Revista dos Tribunais, 2012.

PASSOS, Carlos Roberto Martins. NOGAMI, Otto. Princípios de Economia. São Paulo: Thomson Learning, 2006. 5.ed.

POSNER, Richard. Economic Analysis of Law. 7ed. Boston: Austin: Kluwer. 2007.

SILVA, Ana Paula Ferreira da et al. Indicadores Sociais: Um Estudo Realizado nos Balanços Sociais de Empresas que Receberam o Selo IBASE. In: Revista de Administração, Contabilidade e Sustentabilidade. v. 2, n.1, p.72-86, jan-abr 2012.

SOUSA, Fabricio Alves de et al. Responsabilidade Social Empresarial: Uma Análise sobre a Correlação entre a Variação do Índice de Sustentabilidade Empresarial (ISE) e o Lucro das Empresas Socialmente Responsáveis que compõem esse İ́ndice. In: Revista de Administração, Contabilidade e Sustentabilidade. v. 1, n.1, p.52, 2011. 
Personalidade Acadêmica Homenageada:

Carlos Aurélio Mota de Souza (Universidade Ibirapuera - UNIB)

TENÓRIO, Fernando Guilherme. Responsabilidade Social Empresarial. Teoria e Prática. Rio de Janeiro: Editora FGV, 2004

TONOLLI, Bárbara Beirão; ROVER, Suliani; FERREIRA, Denize Demarche Minatti. Influência dos Investimentos Ambientais e dos Indicadores Econômico-Financeiros na Seleção de Empresas Para Compor o Índice de Sustentabilidade Empresarial (ISE). In: Revista Catarinense da Ciência Contábil. Florianópolis, SC, v.16, n.48, p.69-85, maio/ago. 2017.

TUPY, Oscar. Investimentos em meio ambiente, responsabilidade social e desempenho econômico financeiro de empresas no Brasil. In: Revista de Estudos Politécnicos. V. VI, n.10, 073-086. 2008.

VAN DER LAAN, G.; VAN EES, H.; VAN WITTELOOSTUIJN, A./ Corporate social and financial performance: An extended stakeholder theory, and empirical test with accounting measures. In: Journal of Business Ethics. 2008. V. 79, № . 3. pp. 299-310. 